\title{
Conversação e convenções literárias na Sátira II 6 de Horácio
}

\author{
VICENTE DE P. IANNINI \\ Departamento de Letras Clássicas \\ Faculdade de Letras \\ Universidade Federal de Minas Gerais
}

\begin{abstract}
RESUMO: O objetivo deste artigo é tematizar alguns aspectos de conversação como um discurso sobre o sermo na Sátira II 6, de Horácio. Após situar a ação na quinta de Horácio na Sabina, tento mostrar como o poeta cria a impressão de uma conversação real, analisando a variedade de linguagem empregada, e, especialmente, a arte de encaixar um sermo dentro de outro. A fabella que encerra a sátira, pode ser vista, no sentido de Fraenkel, como um ainos, o qual nos permite ver sua função como um gênero insertado e apreciála como um ponto alto no processo de encaixe. A fabella é percebida como um detalhe ornamental que permite a condução da sátira a um finale grandioso. Por fim, aponto algumas convenções literárias de que o poeta se utiliza para tornar verossímil a imagem de descontração sugerida pelo sermo.
\end{abstract}

PALAVRAS-CHAVE: ainos; conversação; convenções; discurso; fabella; Horácio; sátira; satura; sermo.

Horácio fez da sua propriedade, junto às colinas da Sabina, o ambiente em que podia esquivar-se das inquietações da vida agitada da cidade. Livre da rotina de Roma, ali o poeta passava "noites e ceias divinas" (Hor. Sat. II 6 65), junto ao fogo, entretido numa de suas ocupações prediletas: a conversação. Ao longo de sua obra, muitas vezes podemos surpreendê-lo nesse ofício. Sua arte depende, em muito, dessa habilidade. Evidentemente, não se trata da reprodução de falas reais. Tudo se passa num domínio literário em que a situação é artificial, quando não idealizada.

Sem pretender ser exaustivo, meu objetivo é tematizar a conversação como um discurso sobre o sermo $^{1}$, tal qual se encontra na sátira II 6, com ênfase na fabella ${ }^{2}$ (vv. 77 117) que a encerra e que é uma versão sofisticada da deliciosa história do rato da cidade e o rato do campo. Para isso, faço uma pequena incursão pela quinta da Sabina, que forma o ambiente físico e social, e apresento alguns dos tópicos que compõem o cenário em que o sermo se desenvolve: os temas de conversação, sua pretensão filosófica e, sobretudo, a arte de encaixar um sermo dentro de outro. Como subsídio, levanto a questão do tipo de linguagem utilizada e caracterizo a fábula como ainos $^{3}$, no sentido fraenkeliano ${ }^{4}$. Exponho, outrossim, sua função de gênero insertado, já assinalada, aliás, pelos antigos. À medida que conduzo a discussão, apresento uma ou outra convenção literária a que o poeta faz eco. 


\section{Ambiente físico e social: a quinta da Sabina ${ }^{5}$}

A sátira II. 6 contém a primeira menção literária da quinta da Sabina. Presente de Mecenas, a quinta figura em muitas produções do período intermediário da obra do poeta, quando do início da publicação do segundo livro das Sátiras, do primeiro das Epístolas e dos três primeiros das Odes.

Seu encanto reside, em parte, nessa ilusão, que transmite, de podermos acompanhar o poeta numa ceia íntima, em animada conversa com amigos e vizinhos, junto a uma lareira. Muito embora esse possa ser o móvel de nossa curiosidade, o quadro, possivelmente, se ligue a uma convenção literária, cujo modelo se pode identificar: os convidados, livres de legibus insanis (leis insensatas), esvaziam inaequalis calices (copos desiguais), entregando-se livremente ao vinho forte ou fraco, conforme queiram. Não há regras de etiqueta. A cena é convincente:

Prout cuique ..libido est, siccat inaequalis calices conuiua solutus legibus insanis, seu quis capit acria fortis pocula seu modicis unescit laetius... [67-70]

"Os convidados, seguindo cada um o seu desejo, livres de regras insensatas, põem a seco copos desiguais: algum, mais vigoroso, toma vinhos fortes, ou, simplesmente, molha a garganta com um vinho mais suave"6.

Trata-se, certamente, de uma fórmula, de uma convenção, como tantas outras que se encontram semeadas, com maior ou menor arte, ao longo de toda a literatura latina. É a fórmula da bebida que se pode, por exemplo, descobrir no início do Simpósio, de Platão, como o assinalou Leach (Leach, 1993, p. 284), que, para além disso, aponta ainda a construção do banquete horaciano como uma combinação de elementos gregos e romanos. Kiessling (Leach, 1993, p. 285), por sua vez, coloca, como referência básica, a descrição que Cícero faz de Catão na sua propriedade, também na Sabina:

quae quidem etiam in Sabinis persequi soleo conuiuiumque uicinorum cotidie compleo, quod ad multam noctem quam maxime possumus uario sermone producimus (De Sen. 14 46).

"esses hábitos os mantenho mesmo na Sabina: todos os dias, encho a mesa de vizinhos e, com variada conversação, prolongamos o banquete, o mais que podemos, noite a dentro".

De sorte que a pequena vinheta que emoldura a abertura, se traduz, também ela, num quadro aparentemente realístico, que, muitas vezes, foi tomado como indicação topográfica:

Hoc erat in uotis: modus agri non ita magnus

Hortus ubi et tecti uicinus iugis aquae fons

Et paulum siluae super his foret, auctius atque

Di melius fecere... [1-4] 
"Era este o meu desejo: um pedaço de terra não muito grande, onde houvesse um vergel e uma fonte de água perene próxima da casa e, mais acima, um pequeno bosque. Mais e melhor fizeram os deuses".

Portanto, o quadro de abertura reveste-se de elementos fortemente convencionais, o que pode levar o leitor moderno a enganos de interpretação. A sátira de Horácio está repleta dessas armadilhas, como aliás toda a sua obra: são comuns as convenções, seja de caráter social, seja de caráter literário, que ali se encontram.

\section{Tópicos da conversação}

Voltando ao banquete, encontramos, a meio caminho, como que uma chave que nos põe a par das preocupações do satírico. O verso 70 nos informa que naquele ambiente, assim descontraído, "começa a conversação" (sermo oritur), e, nos versos seguintes, tomamos conhecimento não só de uma lista de temas desejados, mas ainda de uma restrição à maledicência.

Ergo sermo oritur, non de uillis domibusue alienis
nec male necne Lepos saltet, sed, quod magis ad nos
pertinet et nescire malum est, agitamus, utrumne
diuitiis homines an sint uirtute beati,
quidue ad amicitias, usus rectumne, trahat nos
et quae sit natura boni summumque quid eius [70-76].

“... e assim nasce nossa conversação, não sobre quintas e casas alheias, nem sobre Lepos (se dança mal ou não), mas sobre o que nos toca mais de perto e que seria inconveniente ignorar: discutimos, sim, se é, por acaso, pela riqueza ou pela virtude que os homens se tornam felizes; ou se é o interesse ou um princípio moral o que nos atrai para as amizades; ou, ainda, qual é a natureza do bem e qual é sua expressão máxima”.

A conversação é também ela nitidamente reflexo de convenções. Sua artificialidade, não obstante se disfarça por uma impressão de naturalidade e de aparência coloquiais: a naturalidade pode ser algo que se obtém, paradoxal que pareça, de maneira artificial. Para nós é um pouco difícil imaginar uma reunião de amigos, sem que se pense numa conversa descompromissada.

Estranhamos a escolha de assuntos de natureza ética, como, para ficar num exemplo, a questão ventilada de se saber "se é pela riqueza ou pela virtude que os homens se tornam felizes" (utrumne/diuitiis homines an sint uirtute beati-73-74). Na realidade, estamos em presença de simples convenção que afeta não só a obra de Horácio, mas ainda o conjunto da produção satírica romana, tendo como modelo os usos literários que os gregos faziam da vertente ética de sua filosofia. Mais ainda, é preciso não esquecer a observação de Fraenkel (Fraenkel, 1966, p. 143) de que se trata evidentemente de simples idealização:

"Nenhum leitor sensato seria levado a crer que os camponeses da região de Vicovaro, quer sotto il buono Augusto quer em qualquer outra 
época, conversariam como se houvessem examinado o De finibus bonorum et malorum de Cícero ou livros semelhantes"7.

Entretanto, sem que isto invalide o que se acabou de dizer, o contínuo retorno, em Horácio, da questão ética, em forma de moral prática, se apresenta de modo quase obsessivo. Na sátira, em especial, sua presença é marcante. A função mais evidente é a de castigar os costumes, através do riso, da mordacidade e da ironia, dentro de limites que o próprio autor se impôs em seu programa satírico. Essa repetição de temas batidos poderia tornar-se tediosa. Por isso, o poeta a reveste sempre de tal coloração que o leitor disso mal se apercebe.

\section{Sátira e diatribe ${ }^{8}$}

Também não é novidade que Horácio fez da sátira um lugar privilegiado da diatribe. É natural que ali se revelem pontos da arte da conversação: de fato a diatribe, de origem helenística, tem, como uma das suas possibilidades, o diálogo. Nas sátiras, este se dá, quase sempre, entre o poeta, em primeira pessoa, e um interlocutor, nomeado ou suposto.

Tudo isso torna a leitura da sátira uma operação difícil. À medida que se avança no texto, surgem barreiras insuspeitadas, tais como o conhecimento pressuposto de seu background histórico e literário ou o domínio de detalhes da vida social romana e de seus valores.

\section{Modalidades de sermo e literatura republicana ${ }^{9}$}

A modalidade de sermo que Horácio empregará nos seus Sermones resulta de itinerário tortuoso, que muito tem a ver com a formação da literatura latina. Por essa ocasião, ainda não se havia estabelecido em Roma uma tradição literária. Os primeiros autores, que nem mesmo eram cidadãos romanos, entregavam-se às mais diversas experiências, como que brincando com a linguagem, numa descoberta feita de criatividade e de espírito inovador.

Até mesmo Lívio Andronico, que passa por ter introduzido oficialmente a literatura em Roma, logo após a derrota de Tarento, provinha da Magna Grécia. Ênio e Pacúvio eram metade oscos, metade gregos. Névio e Lucílio falavam osco; Ácio e Plauto, umbro. Cecílio provinha da Gália Cisalpina, e Terêncio, da África.

Essa heterogeneidade não impediu que a produção desses homens se transformasse em modelos literários e lingüísticos de grande valia para os romanos. A assimilação perfeita à civilização romana de figuras tão díspares, como que em busca de uma linguagem comum, é realmente impressionante. O sucesso de Névio pode ser sentido num epitáfio orgulhoso: após sua morte, já ninguém se lembraria, em Roma, de como se falava o latim.

Talvez uma parcela desses resultados se deva ao fato de que, em que pesem as diferenças entre aqueles autores, a língua literária que criaram esteja, muitas vezes, bem próxima da fala. Em outros termos, a língua literária foi uma estilização da língua falada. Tanto é verdade, que a escrita de Plauto, por exemplo, é uma paródia da fala viva de suas personagens. Não é à-toa que aquele autor seja, para os gramáticos, uma das fontes para o estudo do latim vulgar. 
Por esse motivo, Cícero (Or. 20 67) assim se refere aos cômicos do passado: "Se não fazem versos, nada os diferencia da linguagem do dia a dia"(apud quos, nisi quod versiculi sunt, nihil est aliud quotidiani dissimile sermonis), acrescentando que, até mesmo num gênero como o da tragédia, reflete-se a vitalidade da fala comum. É verdade que aquele autor, a avaliar pelo contexto, se reportava a cômicos gregos, mas a afirmação é aplicável também aos latinos. Assim, a sátira romana primitiva chegou a ser caracterizada como sermo pedestris, algo como linguagem trivial e rasteira, terra-a-terra mesmo. Certamente, muito da impopularidade de Terêncio se deve à tentativa de adaptar suas comédias ao purismo filo-helênico dos Cipiões. O que faria, então, divergir a língua literária da linguagem normal seria tão-somente a modalidade de seu uso.

Mais tarde, já no século I a. C., sente-se, cada vez mais, o influxo grego. Suscitamse novos interesses, como se pode deduzir dos grandes debates acadêmicos de gramática, de retórica ou de filosofia. A norma literária, pouco a pouco, se espelha nos usos da eloqüência. Pode-se ver o reflexo de tudo isso nos debates de um Cícero, no enciclopedismo de um Varrão ou no purismo de um César. Contudo, ainda se dá um certo equilíbrio entre a língua escrita e a língua falada.

Essa efervescência cultural permite, outrossim, um grau de sofisticação teórica que nos surpreende. Cícero, por exemplo, levanta e distingue, com acuidade, toda a gama da variedade dos falares: o latim forense, o latim senatorial, o latim quotidiano, entre outros, e suas modalidades de uso. Noutra direção, Cícero chega mesmo a definir três níveis de enunciação: a prosa quotidiana (oratio soluta), a prosa artística (oratio numerosa) e a poesia (oratio uincta).

Esse ambiente refinado exerce seu influxo na sensibilidade lingüística: a rusticitas, o latim vivo do campo, será sentido como um defeito: de acordo com essa percepção, o homem rústico prolongaria demais as longas e articularia grosseiramente as sílabas, transmitindo uma sensação desagradável de peso. Essa nova sensibilidade via aí um resquício do passado: a rusticitas foi tida como uetustas, uma linguagem arcaizante.

Logo, contrapunha-se à rusticitas a urbanitas, a fala culta, correta, educada, que era veiculada nos círculos elevados de Roma. Da urbanitas chegava-se, com facilidade, à romanitas, e desta, à latinitas. Constrói-se toda uma escala de valores. Com Cícero, a correção linguística associa-se também ao estilo. Essa é a razão por que a descrição linguística dessa época inclui uma valoração estética.

Como resultado desse novo paradigma cultural, a literatura passa a ser regida por um ideal estético que se esforça por conjugar inspiração, propriedade gramatical e capacidade expressiva, a chamada estética clássica.

\section{A guinada clássica}

No período de Augusto, dispõe-se de uma variedade de modelos literários gregos e de uma tradição nacional criativa. Havia, pois, uma experiência estética a considerar. Os escritores então são levados a fundirem a imitação dos gregos com a expressividade latina do passado. A adaptação do verso latino dos gregos não se faz sem muito esforço. Veja-se o célebre passo de Lucrécio (RN. I 136-139): 
multa nouis uerbis praesertim cum sit agendum, propter egestatem linguae et rerum nouitatem.

"É difícil, e isso não me escapa, ilustrar em versos latinos as obscuras invenções dos gregos, mormente quando se trata de achar termos novos, pela pobreza da língua e pela novidade dos temas".

Destarte a poesia se distancia da língua falada. Segue-se um esforço adaptativo de grande envergadura, em que se dão lucros e perdas: se, por um lado, se amplia a riqueza cultural tomada ao passado, por outro, o léxico, agora afastado da antiga criatividade, enrijecese, impõem-se regras ao hexâmetro, a ordem da frase se artificializa. Após Virgílio, tudo se transforma: a literatura jamais será a mesma.

A pressão cultural é avassaladora: de Homero aos líricos arcaicos, dos clássicos à literatura helenística, os poetas se vêem cercados por um passado brilhante, mas pesado. Tal foi o desafio imposto às novas gerações. A elas cabe agora uma disciplina tanto mais rigorosa quanto mais se pratica a imitatio; lembrar que a imitatio tem como corolário a superação dos modelos...! Apesar disso, será esse o grande século da literatura latina, com Virgílio, Horácio, Tibulo, Propércio e Ovídio.

\section{A sátira como estilização do sermo}

Nesse panorama cultural, Horácio, mormente nas suas sátiras, tenta artificialmente restabelecer o uso luciliano do sermo, lançando mão da oratio soluta, a que acima nos referimos. O termo sermo, como está na sátira II 671 , pode ser traduzido como conversação, idéia a que outras variantes semânticas podem reduzir-se (por exemplo, a fala rústica de Ofelo, na sátira II 2 2).

A sátira romana é vista pelos especialistas como uma estilização do sermo, no sentido em que se baseia na conversação. A impressão que Lucílio, seu inventor, e, depois, Horácio que o emula, tentam passar é a de uma conversação casual, solta. Horácio assinala mesmo o caráter 'impoético' dos Sermones que comporta o uso de uma língua falada, viva. A sátira I 439 ss. esclarece melhor esse ponto:

Primum ego me illorum, dederim quibus esse poetis, excerpam numero; neque enim concludere uersum dixeris esse satis, neque, siqui scribat uti nos sermoni propiora, putes hunc esse poetam. Ingenium cui sit, cui mens diuinior atque os magna sonaturum, des nominis huius honorem. Idcirco quidam, comoedia necne poema esset, quaesiuere, quod acer spiritus ac uis nec uerbis nec rebus inest, nisi quod pede certo differt sermoni, sermo merus [...][39-48]

$$
\text { [...] Ergo }
$$

non satis est puris uersum perscribere uerbis, quem si dissoluas, quiuis stomachetur eodem quo personatus pacto pater. His, ego quae nunc, 
olim quae scripsit Lucilius, eripias si tempora certa modosque, et quod prius ordine uerbum est posterius facias, praeponens ultima primis, non, ut si soluas $[\ldots]$

[...] inuenias etiam disiecti membra poetae [53-62].

"Antes de tudo, é bom que eu me exclua do número daqueles a quem concederei o título de poetas, pois não dirás que, para isso, seja suficiente concluir um verso; e, se alguém escreve, como eu, numa linguagem próxima à da conversação, não o terás como um poeta A quem tiver talento, uma inspiração divina e uma voz capaz de elevar-se ao sublime, a esse darás a honra deste título. Eis por que alguns indagaram se a comédia seria, ou não, poesia, já que ali não se encontra nem tom vivo nem vigor expressivo, quer nas palavras, quer nas coisas. Não fora a regularidade rítmica que a faz diferir da prosa, seria mera conversação [...]"

"Não basta, por isso, compor um verso com simples palavras, de modo que, se o tirares do metro, qualquer um exprimirá sua fúria como um pai de comédia. Se às sátiras que hoje escrevo ou àquelas que, em outro tempo, escrevia Lucílio, retirares a quantidade fixa das sílabas e o ritmo, e colocares, em primeiro posto, as palavras que, no verso, vêm depois, antepondo os últimos aos primeiros, não reencontrarás, ao desfazeres estes versos" [...] "os fragmentos do poeta antes retalhado em pedaços."

La Penna (Ramous, 1985, p. XXI-XXX) resume assim a análise desse trecho: "É bem verdade que os elementos 'populares' estão quase todos no léxico, enquanto que muito menos se pode observar na morfologia e na sintaxe", acrescentando que "o caráter quotidiano do sermo é corrigido com a urbanitas e que o estilo de conversação tende a tornar-se mais precisamente um estilo médio, afastado, como a vida do autor, seja do requinte, seja da sordidez e vulgaridade".

Para Ramous (Ramous, 1985, p. XXX), Horácio não é um escritor naturalmente dotado, como o são Virgílio ou Catulo. Esta é uma razão por que o satírico faz parecer espontâneo o que não é natural, mas projetado. Sua poesia é (sem qualquer acepção negativa) uma operação literária, "talvez a mais alta de toda a antiguidade" o que não é contraditório.

Sendo, pois, a língua de Horácio o sermo urbanus, isto é, a fala típica da conversação de pessoas cultas, sua urbanitas e sua latinitas serão revestidas de um disfarce: a arte do satírico fará com que se transmita uma impressão de casualidade, de espontaneidade.

\section{Sermo como gênero do discurso ${ }^{10}$}

Num artigo excelente, Tovar ( Tovar, 1991, p. 64-67) analisa a relação entre satura, sermo e fabella. Segundo ele, sermo nunca chegou a designar um gênero literário, como satura. Aproveitando a oposição entre sermo e contentio, de Cícero (Off 1, 132), e adaptan- 
do teorias do discurso e do gênero de Todorov e de Bakhtin, Tovar coloca o sermo como um gênero do discurso oral, próprio da conversação, procurando mostrar "como se passa de um gênero do discurso, o sermo, a um gênero literário, a sátira". Mais à frente, reforça a idéia, dizendo que "os estudiosos parecem, portanto, admitir a existência de um gênero do discurso, o sermo, que está na base de um gênero literário, a satura. Esta seria a transposição literária daquele".

Na sátira I 4, Horácio contrapõe a linguagem da satura à da épica e à da comédia. Para ele, a satura se aproxima da Comédia Nova, de modo que se lhe tirarmos o metro, também já se disse, o que fica é um sermo merus, quer dizer, um discurso familiar, um modo de falar corrente.

Por outro lado, também os antigos se deram conta dos espaços sociais e sua vinculação literária. Eis por que Cícero, seguido por Horácio, define que tipo de sermo deve ser usado em determinadas situações, para que não se falte ao decorum social. Horácio, por sua vez, deixa transparecer a relação implícita entre a modalidade de sermo para uma dada situação e a sátira. Numa discussão, por exemplo, sobre a franqueza, a libertas, procura ver se é urbanus criticar um amigo ausente ou lançar ataques mordazes contra pessoas, durante um banquete: "Trata-se", continua Tovar (Tovar, 1991, p. 66-67) ) "da conveniência e dos limites da libertas na vida social, no banquete ou reuniões com amigos e, portanto, no gênero do discurso próprio dessas situações, o sermo. Em toda a passagem (v. 78-103), o satírico passa imperceptivelmente de seu comportamento censor na vida (v.80-81) à censura em sua obra (v. 91-93) e termina prometendo que a crítica maliciosa praticada na vida pelo interlocutor, o discurso deste citado nos vv. 90-100, não entrará em sua obra (v. 100103)". "Não creio", continua, "que em parte alguma se ponham em relação de modo tão estreito uma prática discursiva quotidiana e um gênero literário que a incorpora. Por isso encaixa tão bem neste contexto a justificação pessoal que faz Horácio de seus escritos satíricos: seu pai o acostumou a observar criticamente os vícios dos outros como método de autocorreção moral; depois, ele, quando tem tempo, põe suas reflexões por escrito (v. 103104)".

\section{Sátira e fábula}

Levantados os pontos do sermo que interessam, é preciso buscar as razões por que o autor insere no sermo, que é a sátira II 6., um segundo sermo, que é a fabella.

A introdução de uma fábula no corpo de uma sátira se faz com naturalidade, em vista de sua proximidade temática. Horácio costumava inserir fragmentos de fábulas tanto nas sátiras como nas epístolas. Fraenkel aplicava a esses fragmentos o rótulo de ainos/ainoi.

O ainos (para Fraenkel esse é também um ainos) mais desenvolvido de Horácio é a fabella do rato da cidade e o rato do campo (Sat II 6 77-117), o ponto culminante do gênero, ao longo de toda a literatura latina. Não se trata de texto autônomo, inserido que está num conjunto maior e mais complexo. (O poeta latino graceja, colocando essa historieta como uma das aniles fabellae, "contos de velhas". Sua arte, todavia, não foi desafiada nem mesmo por um Fedro).

Antes, porém, de entrar mais fundo nas razões da inserção da fabella, julgo que possa ser útil uma digressão, conquanto um tanto longa, sobre o conceito de ainos, em contraposição a outros termos, como mythos, logos, apólogos. Mais à frente, continuo a digressão, focalizando mais de perto as idéias de Fraenkel sobre aquele conceito. 


\section{Fabella e ainos}

Uma das fábulas gregas mais conhecidas é a do falcão e do rouxinol, em os Trabalhos e Dias, de Hesíodo (v. 202-212). Segundo Janssens (Brunel, 1996, p. 16), é considerada "o mais antigo monumento da fábula grega". Representa apenas dez versos, de um conjunto de 828 , do qual costumamos extraí-la artificialmente. Não se trata, portanto, de um texto autônomo. O poeta apresenta-a com o nome de ainos, que se poderia traduzir aproximadamente por "história", "conto", mais tarde substituído por mythos, logos e mesmo por apologos. A distinção entre esses termos é imprecisa. Ao que parece, pode-se aceitar a sugestão de Chambry (Esopo, 1985, p. XXXI): "Na realidade, ainos é uma antiga palavra empregada pelos poetas para designar um conto, uma historieta em geral; mythos é um termo mais recente e que visa particularmente à ficção que forma o fundo da fábula, ao passo que logos se aplica à fábula, enquanto conto em prosa."

\section{O ainos horaciano, segundo Fraenkel ${ }^{11}$}

Em Roma, a fábula gozou de imensa popularidade. Bastava que um autor citasse alguns versos para que o leitor se lembrasse de seu conteúdo. Essa talvez seja a razão por que Horácio faça uso de fragmentos como os que se encontram em Sát. II 3 299; Ep. I 318 21, e, raras vezes, apresente versões mais desenvolvidas, como em Ep. I 7 9-34 e na sátira II $679-117$.

A esse tipo de composição genérica Fraenkel, já se disse, aplicou o rótulo de ainos. Com esse termo, assinalava a grande habilidade do poeta em lidar com o detalhe ornamental. Ainos poderia, julgo, aplicar-se ainda à fábula como elemento embutido, marcando um momento forte na composição.

Não longe da afirmativa de Fraenkel, temos a opinião de Chambry (Chambry, 1985, p. XXXI) que escreveu o seguinte:

"A última (referindo-se à fábula esópica do cavalo e do veado, introduzida por Lucílio) foi retomada por Horácio que gosta de enriquecer com apólogos suas sátiras e suas epístolas.A do rato da cidade e o rato do campo que encerra a sexta sátira do livro II é uma preciosidade. As da rã que quer ficar tão grande quanto o boi, a do cavalo e do veado, a da raposa de ventre inchado são costuradas com rapidez e vivacidade. Mas quase sempre é por meio de finas e maliciosas alusões que Horácio usa a fábula; é assim que resume, num único verso, o parto da montanha, com que adverte o amigo Celso a não imitar a gralha enfeitada com penas alheias".

Toda essa terminologia é certamente útil. Mas devemos lembrar que Horácio se limita ao uso da forma latina fabella.

\section{Fabella e satura}

Dissemos que a inserção de uma fábula numa sátira se faz com naturalidade. Também se observou que a presença de um ainos costuma dar relevo a um momento da composição. Isso parece dever-se às tensões que ocorrem quando a sátira é uma sátira romana, o que se verá adiante no item 12 .

A sátira romana era única. Derivada da antiga satura dramática, dela guardou feições peculiares, como seu caráter de miscelânea, de variedade, de instabilidade. A caracte- 
rização da satura se reveste de grande complexidade. Assinalo apenas alguns traços de interesse mais imediato.

Pode-se ver a antiga satura como uma representação cênica, em que se mesclam diálogos zombeteiros com danças, mímica, canto e flauta. Supõe-se que a palavra seja um adjetivo destacado da expressão culinária lanx satura ou farcimina satura, aproximadamente prato de variedades. Satura se faz metonímia de variedade. A varietas, tomada num sentido extenso, é, assim, a característica fundamental da satura dramática.

Com Ênio, temos a passagem à satura literária, que se estende aos autores satíricos posteriores. A par de uma métrica variada, Ênio fora, como se sabe, responsável por uma tradição que introduzia na satura conteúdos variados, como autobiografia, fábula esópica, reflexão gnômica e moral, além de uma variedade de estilos. Uma alteração significativa desse panorama deve-se a Lucílio, que definiu o hexâmetro como único metro da sátira.

\section{A inserção da fabella na sátira e suas tensões}

Ao "contaminar" a fábula com processos derivados da sátira, o poeta lograva um ganho expressivo. A fábula tinha recursos limitados: servindo, antes de tudo, como uma vinheta didática para uma lição de cunho moral, a fábula, quando inserida numa sátira, ganhava em mordacidade, ironia, simulação e variedade. A sátira criava uma espécie de tensão, que intensificava o efeito pretendido.

Assim, a fabella do rato da cidade e o rato do campo redobra sua força expressiva, ao ser inserida, no sermo do poeta, como um segundo sermo: a fala de Cérvio. Até então, o sermo do poeta se referia aos sermones aceitos, ou rejeitados, pelos convivas, ou seja, seus temas de conversação. Agora, o satírico cita, por inteiro, um daqueles sermones, como que acidentalmente. O momento oportuno é aquele em que um sermo, não aceito pelo grupo, começava a tomar corpo, a partir do escorregão de alguém, pouco afeito ao decorum do banquete: o conviva "exaltava as riquezas solícitas de Arélio" (v. 78). A descontração do ambiente é que permitia a "correção" do amigo. Cérvio concretiza, de maneira quase sensorial, através de uma fabella, um gênero didático, a opinião comum sobre um tema moral.

A fabella, gênero insertado, agora parte integrante da sátira, vai servir como um exemplum, uma ilustração de um ponto de vista moral. Como tal, sua função retórica é ainda uma convenção literária.

\section{O itinerário da fabella}

O ponto de inserção da fabella se faz em quatro versos:

Ceruius haec inter uicinus garrit anilis

Ex re fabellas. Siquis nam laudat Arelli

Sollicitas ignarus opes, sic incipit: "Olim

Rusticus urbanum murem mus... [77-80].

"Entre um assunto e outro, Cérvio, um vizinho meu, conversa à-toa desfiando, a propósito, seus contos de velha. E, então, se alguém passa a pôr nas alturas as riquezas de Arélio, desconhecendo as preocupações que trazem, ele principia assim: "Uma vez, é o que dizem, um rato de campo..." 
Rudd (Rudd, 1966, p. 246) observa que "(a fábula), embora contada por um vizinho do campo, mostra o poeta naquilo que tem mais de urbano", ou seja, a pintura da sociedade rural tem como fundo a vida urbana. Sua expressão é culta, calcada, pois, no sermo urbanus.

Por outro lado, a fábula embute um ideário filosófico. Bacon (apud Leach, 1993, p. 286), aproxima-a do Simpósio, de Platão, tomado como modelo, dizendo que "a comparação pode ser útil, induzindo-nos a interpretar esta fábula, semelhantemente à de Platão, como um ato de fala dramatizado cujo sentido está intimamente ligado a circunstâncias contextuais".

Disso, Leach, no mesmo passo, conclui que a substância da fábula poderia ser entendida dentro de um contexto socio-econômico. A moral resultante seria explicitamente econômica: [...] haud mihi uitalest opus hac (v. 115-116) ("não tenho necessidade de uma vida assim"), é o que proclama o rusticus, ao preferir sua segurança familiar: [...] ualeas. Me silua cauusque/tutus ab insidiis tenui solabitur eruo." (v. 116-117) (“Adeus: a floresta e minha toca segura me consolarão com o tenro legume".

Como se vê, o epimythion, a moral da fábula, surge da circunstância, a partir da coisa, (ex re): da exaltação de uma riqueza que inquieta (sollicitas opes).

West faz uma análise detalhada da fabella, comparando-a com a de Esopo (Chambry, 1985, p. 243). O leitor que quiser deliciar-se com esse trabalho poderá encontrá-lo em West (West, 1974, p. 67-80). Limito-me aqui a reproduzir o resumo que Tovar (Tovar, 1991, p. 69-70) apresenta em seu artigo já citado:

"Horácio não se limita a narrar a ceia modesta oferecida pelo rato do campo ao amigo da cidade, o convite correspondente deste em sua mansão urbana, a interrupção catastrófica desta segunda ceia e a despedida do rato do campo, que expressa sua preferência pela pobreza livre e segura da vida no campo. O satírico desenvolveu o conto e o condimentou com sua graça característica. Primeiro fortalece o caráter e comportamento humano dos ratos: ao rusticus o caracteriza minuciosamente como um camponês pobre italiano, econômico, mas, ao mesmo tempo, generoso com seu hóspede; ao urbanus, como um "gourmet" mundano. Face à fábula esópica, também é mais complexo o desenvolvimento dramático, porque em II 6 o urbanus não convida o amigo simplesmente para jantar, mas para mudar de vida, convida-o a deixar o incômodo do campo e a empreender com ele o caminho da felicidade. No discurso de convite (90-97), West assinalou ecos platônicos em meio ao jargão epicurista, mais abundante (cf. dum licet, mortalis), e algumas ressonâncias de estilo elevado e lucreciano. O estilo elevado mantém-se depois, tanto na narração da viagem dos ratos durante a noite para a cidade, que recorda a dos heróis épicos que se introduzem subrepticiamente nas fortificações dos inimigos (cf. Il. 10, 252-253 e 297 e En. 9, 224), como na descrição da sala de jantar da casa em que se celebra a ceia urbana, com seus leitos de marfim cobertos de colchas cor de púrpura (97-105), que recorda Catulo 64 48-49. Estes versos estão repletos de linhas "Golden Type" e ressonâncias épicas."

West (West, 1974, p.70-80) assinala os processos que dão à fábula seu impulso mais arrojado, descrevendo sucessivamente três categorias de antropomorfismos: os ratos e a dieta (v. 82-89, 102-111), os ratos e a filosofia (v. 90-97) e os ratos e a épica (v. 97-105). 
Tece, a seguir, considerações em torno das relações entre fábula e sátira, e termina com a apresentação de uma tradução curiosa da fabella, do séc. XV, de Robert Henryson, em suas Morall Fabillis of Esope the Phrygian.

\section{Traços coloquiais na primeira parte (v. 1-76)}

A sátira apresenta toda uma seqüência de atos de fala que recordam algum tipo de elemento coloquial. Digo recordam, porque, como vimos, as falas não são calcadas diretamente na linguagem oral popular, como acontece, freqüentemente, em Plauto, mas numa linguagem urbana, com traços evidentes de elaboração.

Um primeiro exemplo está na transmissão de algumas preces caricaturadas destinadas a dobrar os deuses, no estilo do ut des, preces que o poeta jura não dirigir nunca a Mercúrio, limitando-se a esta:

\section{[...] Bene est. Nil amplius oro,} Maia nate, nisi ut propria haec mihi munera faxis [4-5].

“Assim está bem. Não peço mais nada, ó filho de Maia, senão que me faças estes bens plenamente meus."

Seguem-se preces que, à semelhança do discurso de Cérvio, são sermones encaixados no sermo do poeta:

[...] "O si angulus ille

proximus accedat, qui nunc denormat agellum! [8-9]

"Oh! Se eu pudesse acrescentar aquele cantinho que, logo ali na divisa, faz meu terreno tão irregular!”

O si urnam argenti fors quae mihi monstret, ut illi

thesauro inuento qui mercennarius agrum

illum ipsum mercatus arauit, diues amico

Hercule! [...] [8-13]

"Oh! Se o acaso me mostrasse uma urna cheia de dinheiro, como aconteceu àquele homem que, recebendo por dia de trabalho, achou um tesouro e ficou rico, com a proteção de Hércules, podendo comprar o mesmo terreno que, então, passou a cultivar como seu!"

Essa última prece, para além de ser também um sermo encaixado em outro, contém ainda um ainos, fragmento de um apólogo perdido. Mais à frente, encontramos a figura de impertinentes que atropelam o poeta com pedidos de favor ou com repreensões: [...] "Heia, Ine prior officio quisquam respondeat, urge" [24-25]; "Quid uis, insane, et quas res agis?" [29]; ["tu pulses omne quod obstat, / ad Maecenatem memori si mente recurras." [30-31] ("Vamos! mais rápido! Que ninguém antes de ti ofereça seus serviços de amizade!" [...] “Que queres, estás louco? que fazes?” [..] “Arredas qualquer obstáculo, com a cabeça só em Mecenas, quando corres para a sua casa!”). 
E, assim, podemos acompanhar a caminhada agitada do poeta pelas ruas de Roma, em meio a mil recados:

\section{[...] - Ante secundam}

Roscius orabat sibi adesse ad puteal cras.

- De re communi scribae magna atque noua te

orabant hodie meminisses, Quinte, reuerti

- Imprimat his, cura, Maecenas signa tabellis.

- Experiar [...] Si uis potes [...] [34-39].

"Róscio te pede que estejas amanhã junto ao Puteal, antes das oito". "Os secretários te pediram, Quinto — estás lembrado? — que voltasses a tempo para um novo e importante negócio, de interesse comum. - Vê se consegues que Mecenas coloque seu sinete nestes documentos. - Vou tentar! — Se quiseres, está a teu alcance!".

Uma conversa com Mecenas sobre ninharias simula uma naturalidade maior ainda:

[...] - Hora quota est? - Thraex est Gallina Syro par?

- Matutina parum cautos iam frigora mordent [44-45].

“- Que horas são? - Será que Galina, aquele gladiador trácio, pode enfrentar Siro? - Esse frio da manhã já começa a castigar quem não foi previdente!"

Mais à frente, exclama alguém, ao ver o poeta em companhia de Mecenas:

$$
\text { [...] - Fortunae filius ! [49]. }
$$

"Ó filho da Fortuna!"

Outro tenta arrancar um segredo de Estado:

\section{[...] O bone (nam te}

scire, deos quoniam propius contingis, oportet), numquid de Dacis audisti? - Nil equidem. - Vt tu semper eris derisor! At omnes di exagitent me, si quicquam [51-55].

"Meu querido, de certo o sabes, já que vives em contato com os deuses, ouviste falar alguma coisa a respeito dos dácios? — Eu, nada! Sempre fazes pouco caso! - Que todos os deuses me confundam, se eu souber alguma coisa!"

Um último quer obter informações a respeito da distribuição de terras aos soldados: 
— Quid? Militibus promissa Triquetra

praedia Caesar an est Itala tellure daturus? [55-56].

“- E então? As terras prometidas aos veteranos César as dará na Sicília ou na Itália?"

\section{Traços coloquiais na fabella}

Vimos que a fabella é o único sermo integralmente transcrito na sátira. Dissemos, ainda, que ela começa como uma fala desprentensiosa e que sua elaboração se processa num nível propositadamente superior ao tom geral da sátira. No entanto, os traços coloquiais estão também presentes, mas são de outra qualidade. De fato é aqui que podemos acompanhar um pouco melhor o efeito da 'saturização' dos dois gêneros mesclados: sátira e fábula. A primeira fala é a do rato da cidade:

- "Quid te iuuat, inquit, amice, praerupti nemoris patientem uiuere dorso?

Vis tu homines urbemque feris praeponere siluis? Carpe uiam, mihi crede, comes, terrestria quando Mortalis animas uiuunt sortita, neque ulla est Aut magno aut paruo leti fuga: quo, bone, circa, Dum licet, in rebus iucundis uiue beatus, Viue memor quam sis aeui breuis" [90-97].

"Amigo, disse, que prazer encontras em viver privado de tudo na encosta de um bosque à beira de um abismo? Não preferes, então, os homens e a cidade a estas florestas selvagens? Põe-te a caminho, confia em mim, companheiro, uma vez que as criaturas da terra receberam por sorte almas mortais e, para grandes ou pequenos, não há maneira de escapar à morte. Por isso, meu amigo, enquanto te é concedido, vive feliz em meio aos prazeres, vive lembrado de quanto é breve tua existência".

West (West, 1974, p.74-75) descobre aqui um Horácio cheio de ironias, um Horácio que caçoa impiedosamente dos filósofos, em suma, um mestre da paródia. Nessa fala, as reminiscências são platônicas (bone lembraria ogathé), mas o discurso é francamente pseudoepicurista. Vejam-se, por exemplo, as expressões: dum licet, mortalis.

Há, ainda, traços do estilo elevado de Ênio e da épica didática de Lucrécio: assim, a tmese de quocirca (quo, bone, circa, no v. 95) ou a diérese bucólica, do quinto pé, antecipariam a pomposidade da cena seguinte. A paródia é mesmo abusiva: mediante um antropomorfismo, o satírico zomba da filosofia, colocando-a a serviço de um rato.

A fala, portanto, é finamente elaborada. A aparência de sofisticação filosófica, obtida a poder de uma linguagem calculada, reforça ainda mais a ironia e a paródia, na medida em que se disfarçam os traços coloquiais do discurso. A fala pomposa do rato da cidade deriva da fina observação da conversa habitual de grupos de pessoas de pretenso saber filosófico. Algumas expressões sugerem mesmo isso: quid te iunat, amice; uis tu praeponere; mihi crede, comes; dum licet. Há também o aproveitamente de ditos extraídos da filosofia 
popular, como: neque ulla est aut magno aut paruo leti fuga, ou ainda, uiue memor quam sis aeui breuis.

Por fim a meditação final do rato do campo sugere o tipo de discurso popular, cheio de lugares comuns, que alguém profere quando, vítima de uma decepção, cai na realidade: [...] "Haud mihi uita/ est opus hac", ait, et: "Valeas! Me silua cauusque / tutus ab insidiis tenui solabitur eruo" (v. 115-117), que lembra algo como: "Também eu não preciso disso: fico aqui sossegado no meu cantinho".

\section{Conclusão}

Nem o satirista nem Cérvio concluem qualquer coisa. A fábula se encerra e, com ela, a sátira, mas a interpretação fica para o leitor, que se vê como que lançado em meio ao banquete, transformando-se em ouvinte. E o que ouve? Primeiro a voz do poeta que vai encaixando um sermo no outro. Depois, de novo o poeta que, no entanto, finge transferir o sermo para um outro, e se diverte com o leitor, que o ouve como se ouvisse Cérvio. E qual é a qualidade desse último sermo? Para o poeta, nenhuma. É apenas uma conversa, uma historieta de velha. Menos ainda, é uma "conversa fiada", que é o sentido conjugado de garrit com anilis fabella. Julgo, pois, que o satirista, ainda que lançando mão de recursos sofisticados, ou antes, em razão disso mesmo, conseguiu passar a impressão que queria: a de uma conversação descompromissada.

\section{Notas}

1 - Sermo tem o sentido geral de conversação. Há outras acepções de interesse (cf. tópicos 2, 4, 6 e 7).

2 - Para a caracterização de uma fabella em relação a termos de sentido próximo, cf. os tópicos de 8 a 11 .

3 - Cf. o conceito de ainos nos tópicos de 8 a 10.

4 - No tópico 10 estão algumas idéias de Fraenkel sobre o ainos.

5 - Aproveito aqui algumas observações de Leach (Leach, 1993, p.271-302).

6 - As traduções dos textos latinos são de minha responsabilidade.

7 - As traduções em português de textos críticos em outras línguas são também de minha responsabilidade.

8 - Para o conceito de diatribe e sua relação com o sermo, ver Tovar, 1991, p. 64, n.8.

9 - Cf. Dangel (Dangel, 1995, p.26-35) que resume bem o status quaestionis. Sermo refere-se aqui às modalidades da fala romana, e não aos sentidos de gênero do discurso ou de tópico de conversação. Esses últimos apresentam maior interesse para este trabalho. Dangel resume ainda aqui as principais idéias de Cícero sobre as várias modalidades de oratio.

10 - Para toda esta seção, como, aliás, de modo geral, para o presente trabalho, aproveito várias sugestões do artigo de Tovar (Tovar, 1994).

11 - Fraenkel (Fraenkel, 1966) recoloca em circulação o conceito de ainos. No índice analítico, sob as entradas ainos e fable, de seu livro sobre Horácio (Fraenkel, 1966), encontram-se os principais passos referentes a ainos em Horácio. 


\section{Referências bibliográficas}

ACHCAR, F. Lírica e Lugar-comum. Alguns temas de Horácio e sua presença em português. São Paulo: Edusp - Editora da Universidade de São Paulo, 1994.

BERG, Deena. The mystery gourmet of Horace's satires II. The Classical Journal. Los Angeles, v. 2, p.141-151, 1991.

BICKEL, Ernst. Historia de la Literatura Romana. Madrid. Editorial Gredos, 1982.

BRUNEL, Pierre. La fable est-elle une "forme simple"? Revue de Littérature Comparée. Paris: Didier Érudition, 1996, p. 9-10.

CHAMBRY, É. Notices sur Ésope et les fables esopiques. In: Esopo. Fables. Ed. Chambry. Paris: Les Belles Lettres, 1985.

CÍCERO. Orator. Ed. O.Jahn-W. Kroll. Berlin: 1913; reimpr. 1961.

COLEIRO, E. Tematica e struttura della satira oraziana. Helmantica. v. 31, set.-dez., 1980.

DANGEL, J. Histoire de la Langue Latine. Paris: Presses Universitaires de France, 1995.

ESOPO. Fables. Ed. Chambry. Paris: Les Belles Lettres, 1985.

FRAENKEL, E. Horace. Oxford: Clarendon, 1966.

HORACE. Satires. Ed. Villeneuve. Paris: Les Belles Lettres, 1995.

JANSSENS, J. La Fable et les fabulistes, Office de Publicité éd., Bruxelles, 1955.

LA PENNA, A. Orazio e l'ideologia del principato. Torino, 1963, p. 163

LEACH, Eleanor Winsor. Horace's Sabine Topography. American Journal of Philology, The Johns Hopkins University Press. v. 114, p. 271-302, 1993

ORAZIO. Epistole. Trad. de Mario Ramous. Milano: Garzanti Editore s.p.a., 1985.

Satire. Intr. trad. e not. de M. Labate. Milano: Biblioteca Universale Rizzoli, 1993.

RAMOUS, Mario. Quinto Orazio Flacco. Profilo storico-critico. In: Orazio. Epistole. Trad. de M. Ramous. Milano: Garzanti Editore s.p.a, 1985.

RUDD, Niall. Horace. In: The Cambridge History of Classical Literature. II. Latin Literature. Cambridge: Cambridge University Press, 1982.

The Satires of Horace. Cambridge: Cambridge University Press, 1966.

TOVAR, R. Cortés. Satura, sermo y fabella en Serm. II 6 de Horacio. Mnemosynum C. Codoñer a discipulis oblatum. Edición a cargo de Agustín R. Guerreira. Salamanca: Universidad de Salamanca. p. 63-80, 1991.

WEST, David. Of mice and men. Horace, Satires 2.6.77-117. In: Quality and Pleasure in Latin Literature. Cambridge: Cambridge University Press, p. 67-80, 1974.

WIMMEL, Walter. Zur Form der Horazischen Diatribensatire. Frankfurt am Main: Vittorio Klostermann, 1962. 
IANNINI, Vicente. Conversation and literary conventions in Horace's Satire 2.6. Classica, São Paulo, 11/12, 247-263 1998/1999.

ABSTRACT: This paper aims at discussing some aspects of conversation as a discourse on the sermo in Horace's Satire 2.6. Having situated the action in Horace's Sabine farm, I intend to show how the poet creates the impression of a real conversation, by analysing the language variety used, and especially the art of embedding one sermo within another. The fabella that ends the satire can be viewed as an ainos in the Fraenkelian sense, which allows us to see its function as an inserted genre, and appreciate it as a significant moment in the embedding process. The fabella is perceived as an ornamental detail, leading the satire to its grand finale. Finally, I point out certain literary conventions used by the poet to lend verisimilitude to the relaxed image suggested by the sermo. KEY-WORDS: ainos; conversation; convention; discourse; fabella; Horace; satire; satura; sermo. 